Article

\title{
Enhancing the Oxygen Barrier Properties of Nanocellulose at High Humidity: Numerical and Experimental Assessment
}

\author{
Ali H. Tayeb ${ }^{1,2, *}$, Mehdi Tajvidi ${ }^{2,3}$ (D) and Douglas Bousfield $^{1}$ \\ 1 Department of Chemical and Biomedical Engineering, University of Maine, Orono, ME 04469, USA; \\ bousfld@maine.edu \\ 2 School of Forest Resources, University of Maine, 5755 Nutting Hall, Orono, ME 04469, USA; \\ mehdi.tajvidi@maine.edu \\ 3 Advanced Structures and Composites Center, University of Maine, 35 Flagstaff Road, Orono, ME 04469, USA \\ * Correspondence: ali.tayeb@maine.edu; Tel.: +1-207-581-9516
}

Received: 14 August 2020; Accepted: 16 September 2020; Published: 24 September 2020

\begin{abstract}
Films formed from cellulose nanofibrils (CNFs) are known to be good barrier materials against oxygen, but they lose this feature once placed in humid conditions. To tackle this issue, we applied an optimized pressing condition under elevated temperature to increase the films' density and improve their barrier performance. Furthermore, a water barrier coating was employed on the surfaces to control the moisture uptake at high relative humidity (RH). Neat self-standing films of $\mathrm{CNF}$ with the basis weight of $70 \mathrm{~g} / \mathrm{m}^{2}$ were made through a filtration technique and pressed for $1 \mathrm{~h}$ at $130{ }^{\circ} \mathrm{C}$. The resulting nanostructures were covered on both sides using a water-borne barrier layer. Hot-pressing resulted in a significant reduction in oxygen transmission rate (OTR) values, from 516.7 to $3.6\left(\mathrm{~cm}^{3} /\left(\mathrm{m}^{2}\right.\right.$.day $\left.)\right)$ and to some degree, helped preserve the reduced oxygen transmission at high relative humidity. Introducing $35 \mathrm{~g} / \mathrm{m}^{2}$ of latex coating layer on both sides limited the films' swelling at $90 \%$ RH for about 4 hours and maintained the OTR at the same level. A finite element model was used to predict the dynamic uptake of water into the systems. The model was found to over-predict the rate of water uptake for uncoated samples but gave the correct order of magnitude results for samples that were coated. The obtained data confirmed the positive effect of hot-pressing combined with coating to produce a film with low oxygen transmission rate and potential to maintain its oxygen barrier feature at high relative humidity.
\end{abstract}

Keywords: cellulose nanofibrils; latex coating; oxygen barrier property; relative humidity; hot press

\section{Introduction}

Cellulose nanomaterials (CNs) can form stable self-standing films with promising potentials in packaging applications. When dried into a film or deposited on paper or plastic, they form a dense multi-layer structure that has resistance to gas transport. This is attributed to the large aspect ratio nanoparticles and establishment of extensive inter- and intramolecular hydrogen bonding [1,2]. The transmission of oxygen within such nanostructures is an important factor when it comes to the food-related applications as it is key for food preservation [3]. The low $\mathrm{O}_{2}$ transmission in thin films of cellulose nanofibrils was reported to be close to those of synthetic polymers such as poly(vinyl alcohol) and ethylene vinyl alcohol (EVOH) [4,5]. Aside from self-standing films, surface coating by cellulose nanofibrils (CNF) onto plastic or paper as a layer has great potential; the deposition of cellulose nanomaterials on many commercially available polymers can create an impermeable surface against gases [6,7]. It is demonstrated that the paths of gas diffusion within the nanofibrils are in 
the form of elongated cavities with a cross-sectional size as narrow as $\sim 0.31 \mathrm{~nm}$, and a thin layer of nanocellulose on poly lactic acid (PLA) could give rise to an impervious surface for $\mathrm{O}_{2}, \mathrm{CO}_{2}$ and $\mathrm{N}_{2}$ [8].

The quality of this barrier feature however can be affected by several factors, such as temperature [9], penetrant molecules and pore size [10], crystallinity, fiber morphology (morphology governs the diffusion and tortuosity) [11] and more importantly, humidity of the surrounding environment [12-14]. Among the abovementioned parameters, water sorption/diffusion within such matrices is the most fundamental aspect that directly or indirectly weakens the physical and barrier facets [15]. The hydrophilic nanocellulose can easily absorb the water molecules, causing the cellulosic fibers to swell and disrupt the chain linkages, consequently damaging the airtight network to a significant extent [13]. This points to the sensitivity of nanocellulose barrier properties to moisture and thus it is critical to better comprehend how the rate of oxygen permeation within a nanocellulose layer can be altered by the presence of water being absorbed.

In this context, we mostly refer to the term "water absorption" which involves the water vapor uptake within the bulk of nanocellulose capillary structure, different from the term "adsorption" which takes place only on the fiber surfaces $[16,17]$. Hence, the locus of points is the relative humidity (RH) in the surrounding environment and the equilibrium moisture content (EMC) within nanocellulose-based films. According to the kinetic theory, in such equilibrium state, the moisture mass remains unchanged due to a close desorption and absorption rate [18,19].

Generally, to solve this issue, the water absorption rate should be restrained or fully controlled. One common approach for reducing the water permeation is through coating layer(s) of water-resistant polymers, such as high-density poly ethylene (HDPE), polypropylene (PP), oriented polyethylene terephthalate (OPET) and biaxially oriented polypropylene (BOPP) $[4,20]$. However, these plastics are known to be non-biodegradable, nonrenewable and as a result, problematic for the environment. Moreover, they can be broken down into microplastics and negatively affect the food chain and human health [21]. The protection of the CNF layer on paper with a layer of PLA was described [22] and excellent results were obtained with this bio-based polymer that is expected to be compostable, at least industrially. Methods to help decrease the water sensitivity of $\mathrm{CN}$ films were reviewed and the authors suggest further work into chemical modifications of $\mathrm{CN}$ materials and the use of layers to protect the $\mathrm{CN}$ from moisture [23]. However, the same chemical modifications intended to make $\mathrm{CN}$ particles less water absorbent can interfere with internal hydrogen bonding responsible for the good $\mathrm{O}_{2}$ barrier properties in the first place. In another study, a combined approach using hot-pressing and wax coating was suggested to enhance the CNF films' resistance to organic solvents and make their surface hydrophobic [24]. They reported that while the application of hot-press can increase the films' mechanical properties, wax may control the sensitivity to moisture.

Here, we adopted a novel approach to both enhance the oxygen barrier properties and control the water absorption in films of CNF. We employed a facile filtration method to fabricate films. These films were pressed under elevated temperature to densify the structure and then coated with a water-borne barrier coating mostly made of latex on both sides. The reason behind the application of such coating was twofold. First, the employed formula had a low water permeability and thus should not permit the water vapor through the cellulosic network [25]. Second, the restriction of water passage means a stable oxygen transmission rate (OTR) at humid environment [13]. The attained films were compared with those coated with polyethylene as the reference. The swelling phenomenon under high and low relative humidity was monitored via a traditional gravimetric method as well as through a dynamic measurement of oxygen transmission rate over time. Moreover, a model based on the finite element method was developed to predict the water uptake by the samples in the presence of the barrier layer. The model took into account the moisture dependence of the diffusion coefficient.

\section{Materials and Methods}

A $3 \mathrm{wt} \%$ solids suspension of CNF containing 90\% fines (the fraction of fibril bundles smaller than $200 \mu \mathrm{m}$ in length) was produced by the University of Maine's Process Development Center (PDC) 
from a bleached softwood kraft pulp feedstock. The size distribution is wide, with some fibers less than $40 \mathrm{~nm}$ and other parts over 2 microns. The CNF was diluted to $1 \mathrm{wt} \%$ prior to use.

As illustrated in Figure 1, the $1 \mathrm{wt} \%$ CNF slurry was sonicated for $5 \mathrm{~min}$ at $80 \%$ amplitude and agitated vigorously via a planetary centrifugal mixer for another $5 \mathrm{~min}$ at $2000 \mathrm{rpm}$. The resulting suspension was further diluted and used for the subsequent film preparation via a vacuum-assisted filtration method. Briefly, the $0.1 \%$ solids content suspension of CNF was poured onto the filtration funnel fitted with a filter paper and upon the filtration process, the still wet films were immediately removed and placed between two stainless-steel plates under mild pressure to be oven-dried at $70{ }^{\circ} \mathrm{C}$. The dried films had a basis weight of $70 \mathrm{~g} / \mathrm{m}^{2}$ and were subsequently rewetted and pressed (1500 psi) for one hour at $130^{\circ} \mathrm{C}$. The films' thicknesses were measured using a lab-scale digital thickness gauge showing that they were reduced from 95 to $70 \mu \mathrm{m}$ upon the pressing process.
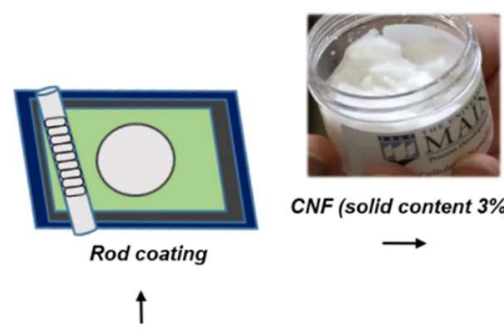

CNF (solid content $3 \%$ )
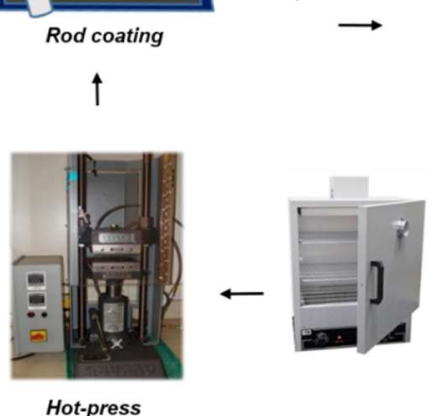

Hot-press

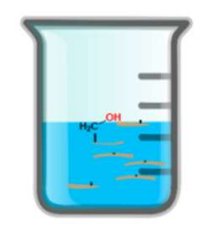

Dispersing in water

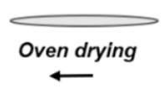

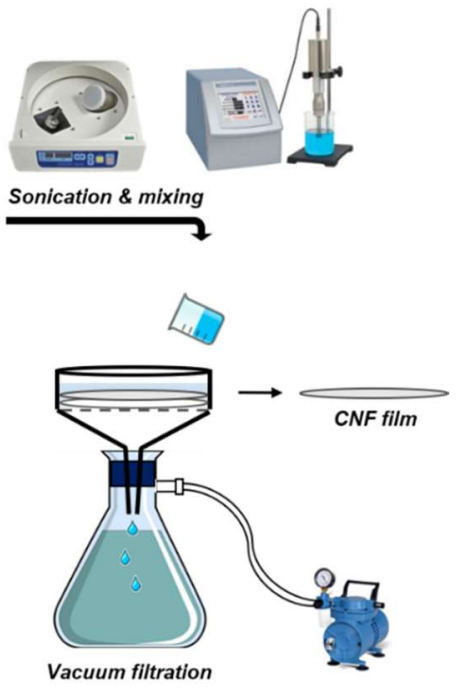

Figure 1. Schematic summary for fabrication process of cellulose nanofibrils (CNFs) self-standing films via vacuum-filtration and pressing.

The dynamic uptake of moisture was obtained by weighing the samples exposed to high humidity $(90 \%)$ under room temperature over the various time [26]. Table 1 shows the moisture content of the samples at various times exposed to saturated air at room temperature.

Table 1. Equilibrium moisture content (EMC\%) of original and modified CNF films as a function of exposure to high humidity overtime. PE: Polyethylene.

\begin{tabular}{ccccccccc}
\hline Sample Code & \multicolumn{7}{c}{ Exposure Time (hour) } \\
\hline & $0.5 \mathrm{~h}$ & $1 \mathrm{~h}$ & $2 \mathrm{~h}$ & $3 \mathrm{~h}$ & $4 \mathrm{~h}$ & $24 \mathrm{~h}$ & $48 \mathrm{~h}$ \\
\hline \multicolumn{7}{c}{ Moisture Content (\%) } \\
\hline CNF & 5.8 & 8.9 & 10.9 & 10.8 & 10.9 & 23.4 & 24.6 \\
CNF-Pressed & 7.1 & 9.9 & 10.7 & 11.7 & 12.9 & 20.2 & 20.5 \\
CNF-Pressed Latex-Coated & 1.5 & 2.5 & 3.4 & 4.4 & 5.3 & 12.3 & 13.5 \\
CNF-Pressed PE-Coated & 0.9 & 1.1 & 1.1 & 1.2 & 1.6 & 3.6 & 5.3 \\
\hline
\end{tabular}

\subsection{Film Coating Procedure}

Coatings ( $35 \mathrm{~g} / \mathrm{m}^{2}$ each side) were applied using a 30\% suspension of latex (OMNOVA Solutions, X12-185) and a rod coater. The latex used in this work had a solid content of $52 \%$ and was a styrene-butadiene latex-based chemistry with particle size of 180-220 nm, and a glass transition temperature of $5{ }^{\circ} \mathrm{C}$. The obtained structures were left in an oven for $15 \mathrm{~min}$ at $70{ }^{\circ} \mathrm{C}$ and analyzed with an oxygen analyzer before and after coating to monitor their oxygen transmission rate at different 
humidities. The latex-coated films had the thickness of $120 \mu \mathrm{m}$. For the reference samples, the same CNF films were coated by a layer of polyethylene (PE) on both sides through the same hot-pressing process. A common commercially available low-density PE from a plastic bag with a thickness of 75 micron was cut and used. The total thickness of PE-coated films reached to $200 \mu \mathrm{m}$.

\subsection{Oxygen Transmission Rate Analysis}

The oxygen transmission rate test was performed via a standard procedure [27], and a Mocon instrument (Ox-Tran Module 2/22, Mocon, Inc., Minneapolis, MN, USA) was used. Samples were conditioned for $12 \mathrm{~min}$ and for each run, the initial individual zero was obtained at the beginning and after every two tests for $15 \mathrm{~min}$. Each testing cycle took $15 \mathrm{~min}$ at $23^{\circ} \mathrm{C}$ under three different relative humidities: $0 \%, 50 \%$ and $90 \% \mathrm{RH}$, and the analyses were terminated upon reaching a plateau region. The permeation area for each film was limited to $5.0 \mathrm{~cm}^{2}$ by a double aluminum layer masking while being exposed to $100 \%\left(\mathrm{O}_{2}\right)$ concentration.

\subsection{Resistance to Grease}

The grease resistance of the coated films was evaluated according to the standard kit-test [28], in which different reagents (marked from 1 to 12 kit number) were first dropped on the films' surface (from a $13 \mathrm{~mm}$ height) and wiped by a cotton ball after $15 \mathrm{~s}$. Any observed stain was interpreted as failure and the reagent number that did not darken the surface was reported as the passed kit number.

\subsection{Modeling of Dynamic Mass Transfer}

Films that are exposed to high humidity absorb moisture on the order of $20 \%$ by weight. The molar concentration of water in the CNF film should be given by:

$$
C_{w}=\frac{\rho_{w} \rho_{c} W}{M_{w}\left(\left(\rho_{c}-\rho_{w}\right) W+\rho_{w}\right)}
$$

where $W$ is the weight fraction of water in the CNF film, $\rho_{c}$ is the density of cellulose $\left(1500 \mathrm{~kg} / \mathrm{m}^{3}\right)$, $\rho_{w}$ is the density of water and $M_{w}$ is the molecular weight of water. Equation (1) comes from the definition of weight fraction, the use of molecular weight to obtain moles of water and densities of water and cellulose to obtain volume. For a moisture weight fraction of 0.2 , the concentration of water in the film is $15,000 \mathrm{~mole} / \mathrm{m}^{3}$. At room temperature, the concentration of water in air at saturation is $1.1 \mathrm{~mole} / \mathrm{m}^{3}$. Therefore, the partition constant between the film and the air is $15,000 / 1.1=14,000$, or the ratio of the water concentration in the solid divided by that of the air.

For CNF films of around $70 \mu \mathrm{m}$ thick, the water vapor transmission rate is around $400 \mathrm{~g} / \mathrm{m}^{2} /$ day [3]. The steady-state diffusion through the film is given by Fick's law at steady state, as

$$
J=D P\left(C_{2}-C_{1}\right) / T
$$

where $J$ is the molar flux rate, $D$ is the diffusion coefficient of water in the film, $P$ is the partition constant, $C_{2}$ and $C_{1}$ are the water concentrations in the vapor phase on each side of the film and $T$ is the film thickness. Therefore, the diffusion coefficient for water diffusion in the CNF film is around $2.4 \times 10^{-12} \mathrm{~m}^{2} / \mathrm{s}$, assuming $\mathrm{P}=14,000$.

For the barrier polymer used with a coat weight of $40 \mathrm{~g} / \mathrm{m}^{2}$ on paper, the WVTR is on the order of $30 \mathrm{~g} /\left(\mathrm{m}^{2}\right.$.day). This gives a diffusion coefficient times the partition constant (DP in Equation (2)) to be $1.6 \times 10^{-9} \mathrm{~m}^{2} / \mathrm{s}$. For simplicity, assuming the same partition constant as the CNF film, the diffusion coefficient for latex is $1.1 \times 10^{-13} \mathrm{~m}^{2} / \mathrm{s}$. Whatever the true value of the partition constant is for the latex films, similar results should be obtained in the model because the partition constant is always multiplied by the diffusion coefficient in the calculations.

The solution to non-steady diffusion into a solid film is found in common textbooks related to diffusion, but in this case, we have three layers and there is the potential that the diffusion coefficient 
may be a function of moisture content of the film. Thus, to solve this problem, a commercial finite element method code (COMSOL, Multiphysics 5.5) was used to model the non-steady diffusion of water into the sample. Wang et al. reviewed the literature in terms of the barrier properties of CNF films [4]. The oxygen transmission rate is known to be a function of the film's water concentration, but clear relationships are not available in the literature.

Figure 2 shows the mesh used and a typical result at short and moderate times. The concentration of $15,000 \mathrm{~mole} / \mathrm{m}^{3}$ is applied to the left and right sides of the computational domain to represent the high moisture content of the solid that would link to water-saturated air. The physics is set to "dilute species" and "non-steady". The middle region is the CNF film that is around $70 \mu \mathrm{m}$ thick. The two regions surrounding the CNF layer represent the barrier coating layers and are assigned a diffusion coefficient of $1.1 \times 10^{-13} \mathrm{~m}^{2} / \mathrm{s}$. In Figure 2, the barrier coating layers are $25 \mu \mathrm{m}$ thick but various thicknesses were simulated. Some cases are also calculated without the barrier layers to simulate the uncoated samples. No flux boundary conditions are applied to the top and bottom of the domains. As time passes, the water concentration in the barrier films and CNF films increases first to the saturation value. Over a longer time, the entire CNF film and barrier films reach the saturation coefficient that corresponds to $20 \%$ moisture by weight. The steady-state diffusion flux of water is obtained by adjusting the boundary conditions to simulate flux through the sample and observing the long-time results. The average concentration of water in the CNF film is calculated by the program using the "derived values" option and averaging the concentration in the region of the CNF layer. This function averages the color values of Figure 2.

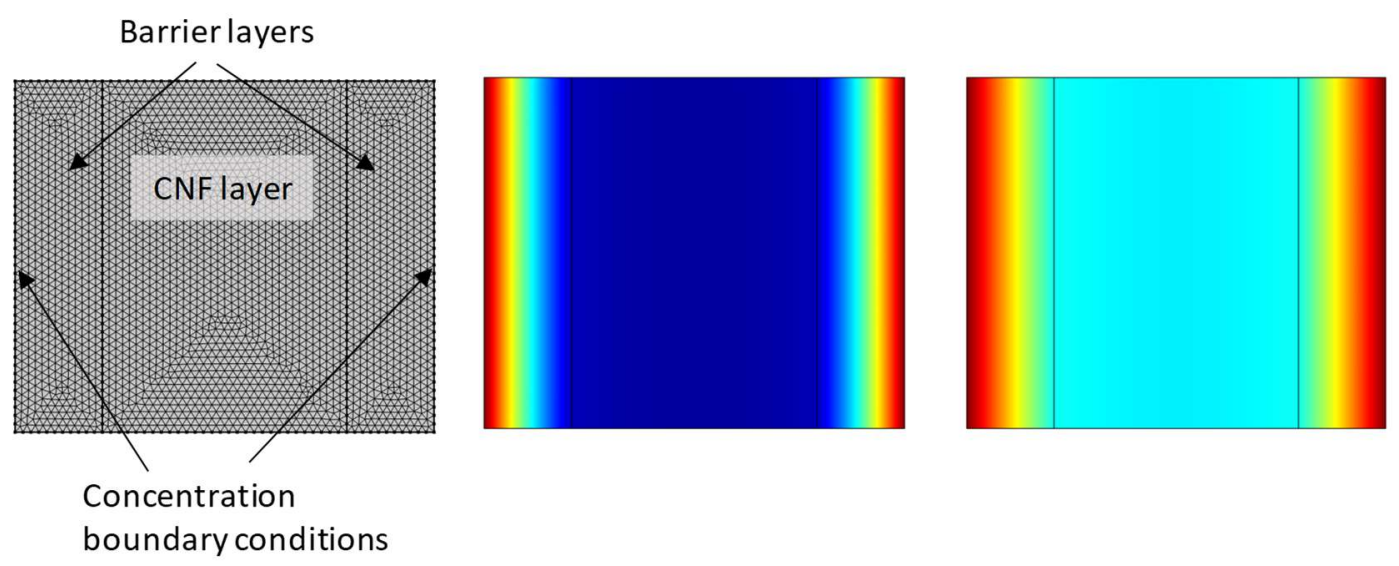

Figure 2. Finite element mesh used (left) and water content at short and moderate times (middle and right), where red shows saturation concentration. Dark blue represents no water content.

\section{Results and Discussions}

\subsection{Oxygen Transmission Rate in the Pressed Films}

It has been shown that pressing can reduce the porosity within CNF films and lead to a denser structure [24]. The goal here is to find out if the combination of pressing and addition of barrier layer can generate any degree of moisture resistance on the system.

Figure 3a, shows that the un-pressed CNF film had an OTR value more than 100 times greater than that of the pressed one at dry conditions. In other words, the OTR was reduced to less than $1 \%$ of its original value upon the pressing process. The time-dependent nature of the results is typical when testing at low humidity in that the OTR values are high, but as the system comes to equilibrium, the OTR drops to a steady state, usually within 8 hours. The reason for these dynamics is not clear and would require further analysis. 


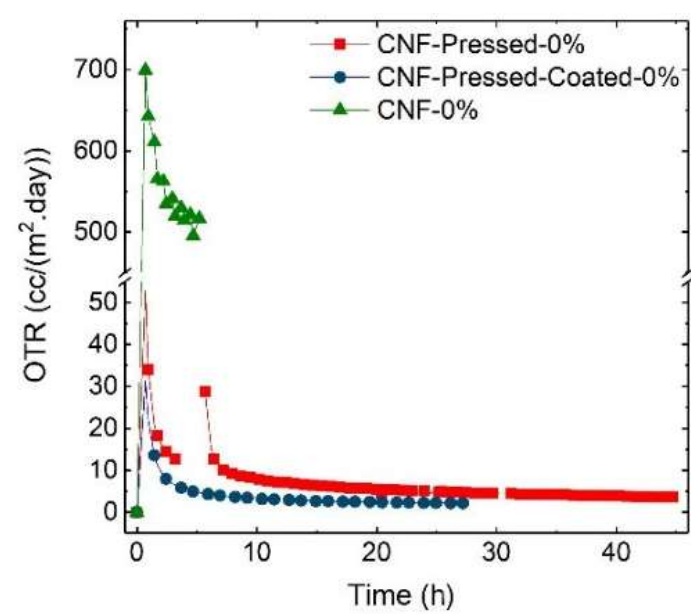

(a)

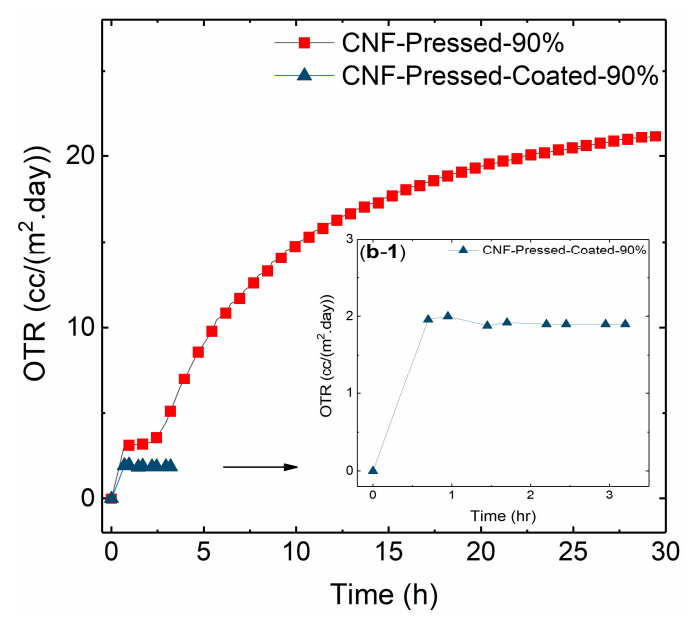

(b)

Figure 3. Dynamic data for the oxygen transmission rate analysis of CNF films upon pressing and coating by latex under (a) $0 \%$ (dry conditions) and (b) $90 \%$ relative humidity (RH), (b-1) is the enlargement of the pressed and latex-coated CNF graph in $(\mathbf{b})$.

The results for OTR testing at $90 \%$ relative humidity are shown in Figure $3 \mathrm{~b}$. For the un-pressed sample, the values became too large for the testing device and the result is not shown. OTR values start low but increase over time. For the uncoated CNF film, this increase continues for around $24 \mathrm{~h}$ before the equipment stops the test, indicating a steady state is reached. It was reported by our group and others that OTR increases at high humidities $[13,29]$. The changes seen in Figure $3 b$ are likely caused by the water uptake of the CNF film and the subsequent swelling due to the loss of hydrogen bonding. Although the OTR showed a markable increase upon changing the $\mathrm{RH}$ from $0 \%$ to $90 \%$, from 3.66 to $21.16\left(\mathrm{~cm}^{3} /\left(\mathrm{m}^{2}\right.\right.$.day $\left.)\right)$, yet, the absolute values are still significantly lower than that of the un-pressed CNF films, $516.76\left(\mathrm{~cm}^{3} /\left(\mathrm{m}^{2}\right.\right.$.day)) at dry conditions (Table 2$)$. The experiment with un-pressed films at high humidity failed due to the oxygen transmission rate way above the sensors capacity. To control the swelling phenomenon at higher $\mathrm{RH} \%$, CNF films, after being pressed, were coated by a latex-based formula with low water vapor transmission rate. The OTR results of the coated film over time are shown in Figure 3(b,b-1). For these coated samples, a changeless state is detected by the equipment in 4 hours. The quick steady state for the coated sample is because the barrier layer probably slows down the water uptake to a level that seems to be a stable early in the test, leading to the stabilization of OTR.

Table 2. Oxygen transmission rates (OTR) and grease resistance test for CNF films under 0\% and $90 \%$ relative humidity $(\mathrm{RH})$.

\begin{tabular}{ccccc}
\hline Sample Code & CNF RH\%: & CNF RH\%: $\mathbf{9 0}$ & $\begin{array}{c}\text { CNF-Pressed } \\
\text { RH\%: } \mathbf{0}\end{array}$ & $\begin{array}{c}\text { CNF-Pressed } \\
\text { RH\%: } \mathbf{9 0}\end{array}$ \\
\hline Kit Test & 12 & 12 & 12 & 12 \\
OTR $\left(\mathrm{cm}^{3} /\left(\mathrm{m}^{2}\right.\right.$-day $\left.)\right)$ & 516.76 & - & 3.66 & 21.16 \\
\hline
\end{tabular}

When the films are covered by a PE layer, shown in Figure 4, the results also show that within four hours, the OTR is steady and not changing with time for three different humidities. This confirms that the change in OTR by the other films past four hours is a result of moisture interaction with the CNF layer. These results also affirm that the short-time results with the water-based coating are caused by good water barrier layers on the CNF film. 


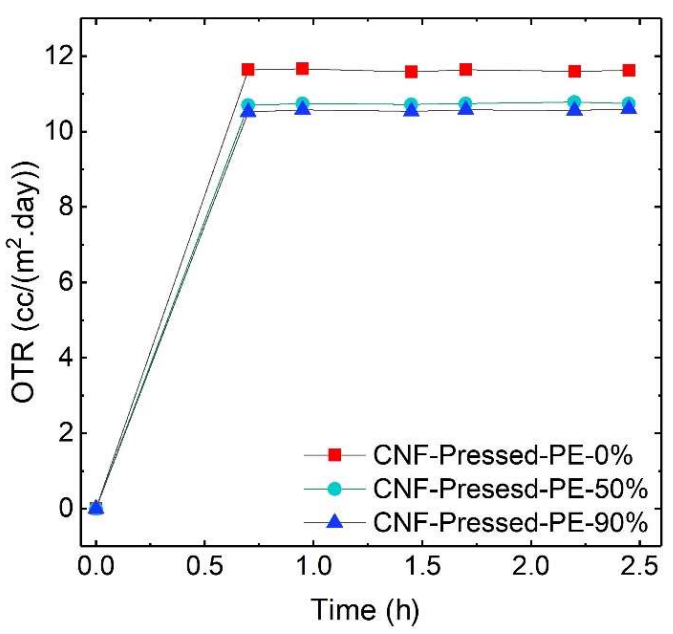

Figure 4. Oxygen transmission rate (OTR) dynamic results for pressed CNF films laminated with polyethylene (PE) film for three values of relative humidity.

The polyethylene-coated films were left in the humid conditions for an even longer time, while no change in OTR values were seen. The employment of polyethylene as a coating material with low inherent water vapor transmission rate was to provide a reference condition, and also confirms that the observed swelling and rise in the OTR seen in Figure $3 \mathrm{~b}$ can be avoided if no water vapor enters the matrix. Although the OTR values did not show a remarkable difference upon the deposition of the coated latex layer at $0 \%$ humidity, no increase in oxygen transmission rate was observed either once increasing the relative humidity to $90 \%$. In case of longer exposure of latex-coated films to the humid environment, a gradual increase in the OTR was seen (data not shown); however, it is still confirmed that the addition of the latex layer could delay the films' H-bond disruption for at least $4 \mathrm{~h}$. Since the OTR analyzer did not detect any significant change within the last 5 analyses, the test was terminated. The OTR analysis stops once 5 consecutive measurements do not deviate more than $1 \%$.The attained oxygen transmission analysis agrees fairly well with the results obtained from the water absorption kinetic test, where samples with lower water absorption values had lower OTR at higher relative humidity. The equilibrium moisture contents obtained in our experiments for both pressed and un-pressed CNF samples are in agreement with those reported for CNF using dynamic vapor sorption analysis [15].

Table 2 summarizes the final OTR values as well as grease resistance (kit) tests obtained from the studied films upon pressing. Both pressed and un-pressed samples could pass the kit number 12, which is the highest resistance to grease.

\subsection{Experiment and Simulation Comparison}

Initial results of the model indicate that the time scale for the CNF film to saturate with water was much more rapid than the time it took for oxygen transmission rate to be constant in the samples and more rapid than the water uptake recorded in Table 1. For the diffusion coefficient that gives the steady water vapor transmission rate, the time for the CNF film to saturate was on the order of a few minutes, as shown in Figure 5. Assuming that the oxygen transmission rate of the CNF film depends on moisture content, the time for the OTR to reach a steady level in the experiments with CNF films was on the order of several hours. Also, in Table 1, the time for the samples to saturate was well over four hours. Even when the diffusion coefficient increased by a factor of ten, the predicted response was rapid. Only when the diffusion coefficient was a factor of 100 smaller than the steady-state value did the model predictions agree with Table 1 and the OTR results, as shown in Figure 5. 


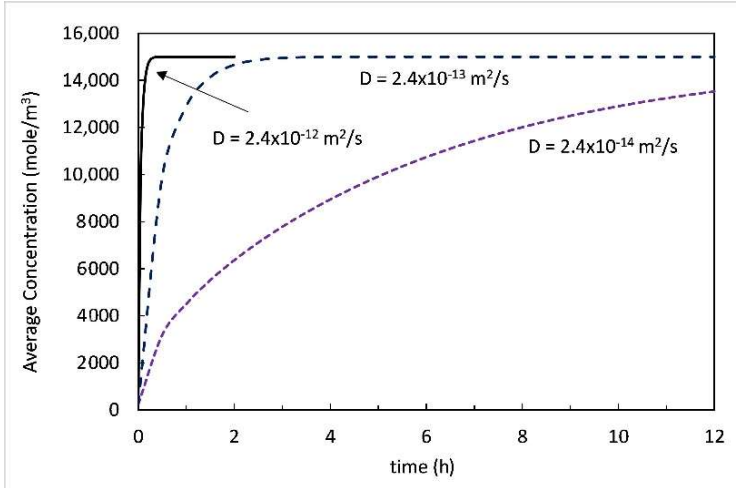

Figure 5. Predicted average water content of a CNF film with no barrier layer for various values of the CNF-water diffusion coefficient.

The results of Figure 5 compared to those of Figure 3 and Table 1 are hard to explain. The parameters in the model are the film thickness, the diffusion coefficient and the saturation value. All three of these values are well known from lab experiments, especially within an order of magnitude. It could be that in the OTR test, the rate that water vapor reaches the CNF layer is limited by the equipment or the mass transfer coefficient between the CNF film and the air. Some calculations indicate that the mass transfer coefficient between the film and the air would have to be on the order of $10^{-5} \mathrm{~m} / \mathrm{s}$ to influence the results: this value is much lower than normal mass transfer coefficients for similar situations. There could also be a time-dependent factor that controls the rate that CNF can absorb water. $\mathrm{CNF}$, when exposed to moist air, may take time to swell the structure, allowing for the material deeper in the film be more accessible to water transport.

One other possible explanation is that the water vapor diffusion coefficient itself is a function of water content in the CNF film. More complex forms of this relationship could be explored, but the purpose here is to attempt to explain the general behavior.

For Figure 5, the diffusion coefficient that is used is the value obtained from steady-state mass transfer through a CNF film exposed to high humidity on one side. Therefore, the CNF film should be close to its saturation value. However, in the experiments, the CNF films start out as bone dry. The value of the diffusion coefficient of water in CNF could be a function of water vapor content. To study this issue, the diffusion coefficient was inserted as a function of concentration in program in the form of $D=A C$, where $A$ is a constant with units of diffusion coefficient divided by concentration $\left(\mathrm{m}^{5} /(\right.$ mole s) $)$ and $C$ is the local concentration of water. At low values of $C$, the diffusion coefficient is locally small, but as $C$ reaches the saturation state, the value of $D$ obtained from the steady-state diffusion results is calculated. When diffusion coefficient is input as a function of concentration, the results in Figure 6 are attained. The dynamics are reduced because the diffusion coefficient of the dry CNF is small and increases to the full value only when the region is saturated. However, the changes in the predictions are minor and do not explain the large difference between the dynamics of the OTR values compared to Figure 5.

For the latex used here, the diffusion coefficient of water through the layer was determined to be $1.6 \times 10^{-9} \mathrm{~m}^{2} / \mathrm{s}$, which includes the partition coefficient. Excluding the partition parameter, the diffusion coefficient should be $1.0 \times 10^{-13} \mathrm{~m}^{2} / \mathrm{s}$. By having a 35 micron-thick coating layer on each side of the CNF film, the result in Figure 7 is predicted. The data are now in the correct range of the dynamics of Table 1 and Figure 3, in that when the barrier layer is present, the film is predicted to take around 12 hours to saturate. This is still more rapid than the observed value in Table 1 but is the correct order of magnitude. If the diffusion coefficient of the barrier layer was a factor of ten smaller, also shown in Figure 7, the water uptake by the CNF film would be much slower: it would take around 48 hours for the film to saturate. Table 1 shows that the coated and the PE-laminated samples are still increasing in weight after $48 \mathrm{~h}$. Note that the curve is flat for the small value of diffusion coefficient 
within the first four hours in Figure 7-this is the time it takes for moisture to finally get through the barrier layer.

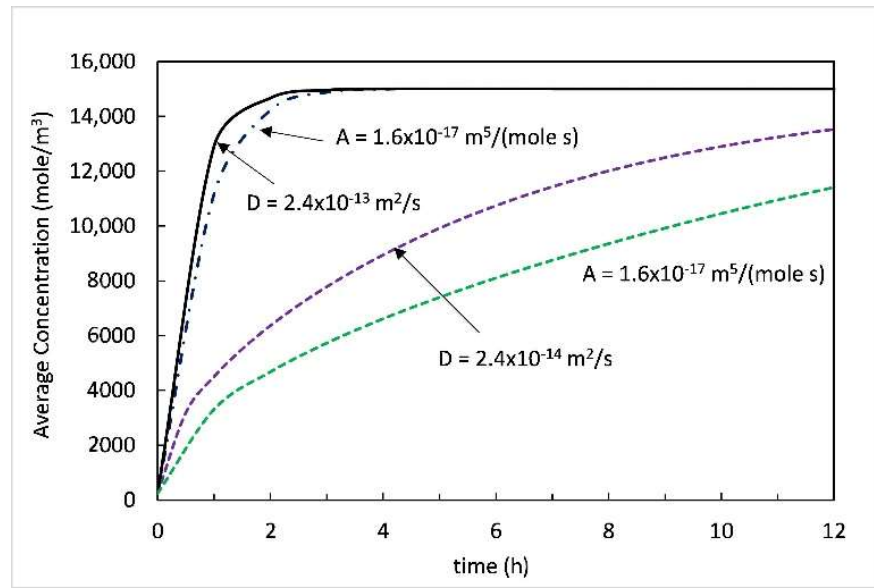

Figure 6. Water absorption results when diffusion coefficients are set or when they are function of concentration as $D=A C$.

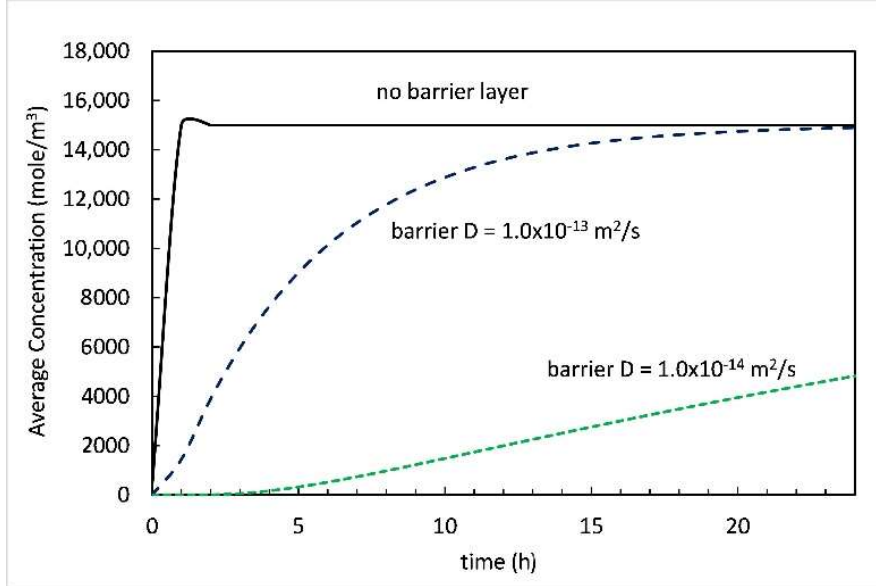

Figure 7. Water absorption in CNF predicted by the model for no barrier layer and for a barrier layer on each side, of $35 \mu \mathrm{m}$ thick, with two different diffusion coefficients.

While the model predictions at this point are giving the correct trends, more work is needed to understand these types of systems. The barrier layer may interact with the CNF film to generate a layer that has unique barrier properties. The CNF film seems to absorb water slower than would be expected based on its diffusion coefficient. This points to a kinetic-type phenomenon where the hydration of a hydrogen bond takes a finite amount of time. The water barrier coating and the PE layer clearly protect the CNF from moisture, but with long exposure times to humidity, this protection is limited.

\section{Conclusions}

In this study, we examined the effect of pressing and the subsequent densification on CNF barrier performance and found that once fibers are fully packed, a significantly higher barrier quality can be achieved. The studied films in this work showed OTR values almost 100 times lower once pressed at $130^{\circ} \mathrm{C}$. This densification helps the samples resist moisture penetration at high-humidity environments. Coatings and PE films do delay the penetration of water into the CNF to give good oxygen barrier properties, even at high humidities. The water absorption is predicted by the model to be much more rapid than the measured values and the OTR dynamics indicate using a diffusion coefficient obtained from steady-state diffusion experiments. Accounting for a diffusion coefficient as a function of water 
concentration did not explain this result. The model does predict the correct order of magnitude and trends when barrier layers are included. All the studied films showed high grease resistance even at high $\mathrm{RH}$ by passing the Kit No.12. Overall, in addition to outperforming the regular CNF films in terms of $\mathrm{O}_{2}$ permeability, the thermally pressed films have the potential to maintain their quality in humid environments that are not tolerable for neat CNF films reported in the literature. Thus, this presented system is suggested as an oxygen barrier material especially where the package is surrounded by a humid condition.

Author Contributions: Conceptualization and methodology, A.H.T., M.T. and D.B.; validation, A.H.T.; original draft preparation, A.H.T.; writing-review and editing, A.H.T., M.T. and D.B. All authors have read and agreed to the published version of the manuscript.

Funding: This research was partially funded by U.S. Endowment for Forestry and Communities (P3Nano), grant number E17-20. This project was also supported by the USDA National Institute of Food and Agriculture, McIntire-Stennis. Project \#041616.

Acknowledgments: The authors would like to thank the funding agencies as described above for the financial support of this project.

Conflicts of Interest: The authors declare no conflict of interest.

\section{References}

1. Moon, R.J.; Martini, A.; Nairn, J.; Simonsen, J.; Youngblood, J. Cellulose nanomaterials review: Structure, properties and nanocomposites. Chem. Soc. Rev. 2011, 40, 3941-3994. [CrossRef] [PubMed]

2. Tayeb, A.H.; Amini, E.; Ghasemi, S.; Tajvidi, M. Cellulose Nanomaterials-Binding Properties and Applications: A Review. Molecules 2018, 23, 2684. [CrossRef] [PubMed]

3. Tayeb, A.H.; Tajvidi, M. Sustainable Barrier System via Self-Assembly of Colloidal Montmorillonite and Cross-linking Resins on Nanocellulose Interfaces. ACS Appl. Mater. Interfaces 2018, 11, 1604-1615. [CrossRef]

4. Wang, J.; Gardner, D.J.; Stark, N.M.; Bousfield, D.W.; Tajvidi, M.; Cai, Z. Moisture and Oxygen Barrier Properties of Cellulose Nanomaterial-Based Films. ACS Sustain. Chem. Eng. 2018, 6, 49-70. [CrossRef]

5. Aulin, C.; Gällstedt, M.; Lindström, T. Oxygen and oil barrier properties of microfibrillated cellulose films and coatings. Cellulose 2010, 17, 559-574. [CrossRef]

6. Balea, A.; Fuente, E.; Monte, M.C.; Merayo, N.; Campano, C.; Negro, C.; Blanco, A. Industrial Application of Nanocelluloses in Papermaking: A Review of Challenges, Technical Solutions, and Market Perspectives. Molecules 2020, 25, 526. [CrossRef]

7. Yook, S.; Park, H.; Park, H.; Lee, S.Y.; Kwon, J.; Youn, H.J. Barrier coatings with various types of cellulose nanofibrils and their barrier properties. Cellulose 2020, 27, 4509-4523. [CrossRef]

8. Roilo, D.; Maestri, C.A.; Scarpa, M.; Bettotti, P.; Egger, W.; Koschine, T.; Brusa, R.S.; Checchetto, R. Cellulose Nanofibrils Films: Molecular Diffusion through Elongated Sub-Nano Cavities. J. Phys. Chem. C 2017, 121, 15437-15447. [CrossRef]

9. Bayer, T.; Cunning, B.V.; Selyanchyn, R.; Nishihara, M.; Fujikawa, S.; Sasaki, K.; Lyth, S.M. High temperature proton conduction in nanocellulose membranes: Paper fuel cells. Chem. Mater. 2016, 28, 4805-4814. [CrossRef]

10. Fukuzumi, H.; Saito, T.; Iwamoto, S.; Kumamoto, Y.; Ohdaira, T.; Suzuki, R.; Isogai, A. Pore size determination of TEMPO-oxidized cellulose nanofibril films by positron annihilation lifetime spectroscopy. Biomacromolecules 2011, 12, 4057-4062. [CrossRef]

11. Fukuzumi, H.; Saito, T.; Isogai, A. Influence of TEMPO-Oxidized Cellulose Nanofibril Length on Film Properties. Carbohydr. Polym. 2013, 93, 172-177. [CrossRef] [PubMed]

12. Belbekhouche, S.; Bras, J.; Siqueira, G.; Chappey, C.; Lebrun, L.; Khelifi, B.; Marais, S.; Dufresne, A. Water sorption behavior and gas barrier properties of cellulose whiskers and microfibrils films. Carbohydr. Polym. 2011, 83, 1740-1748. [CrossRef]

13. Tayeb, A.H.; Tajvidi, M.; Bousfield, D. Paper-Based Oil Barrier Packaging using Lignin-Containing Cellulose Nanofibrils. Molecules 2020, 25, 1344. [CrossRef]

14. Zheng, M.; Tajvidi, M.; Tayeb, A.H.; Stark, N.M. Effects of bentonite on physical, mechanical and barrier properties of cellulose nanofibril hybrid films for packaging applications. Cellulose 2019, 26, 5363-5379. [CrossRef] 
15. Guo, X.; Wu, Y.; Xie, X. Water vapor sorption properties of cellulose nanocrystals and nanofibers using dynamic vapor sorption apparatus. Sci. Rep. 2017, 7, 14207. [CrossRef] [PubMed]

16. Tayeb, A.H.; Hubbe, M.A.; Zhang, Y.; Rojas, O.J. Effect of Lipoxygenase Oxidation on Surface Deposition of Unsaturated Fatty Acids. Langmuir 2017, 33, 4559-4566. [CrossRef]

17. Thybring, E.E.; Kymäläinen, M.; Rautkari, L. Experimental techniques for characterising water in wood covering the range from dry to fully water-saturated. Wood Sci. Technol. 2018, 52, 297-329. [CrossRef]

18. Fredriksson, M.; Thybring, E.E. Scanning or desorption isotherms? Characterising sorption hysteresis of wood. Cellulose 2018, 25, 4477-4485. [CrossRef]

19. Thybring, E.E.; Glass, S.V.; Zelinka, S.L. Kinetics of Water Vapor Sorption in Wood Cell Walls: State of the Art and Research Needs. Forests 2019, 10, 704. [CrossRef]

20. Rezaei, M.; Mohseni, M.; Yahyaei, H. A study on water and oxygen permeability of BOPP coated with hybrid UV cured nanocoatings. Prog. Org. Coat. 2016, 99, 72-79. [CrossRef]

21. Smith, M.; Love, D.C.; Rochman, C.M.; Neff, R.A. Microplastics in Seafood and the Implications for Human Health. Curr. Environ. Health Rep. 2018, 5, 375-386. [CrossRef] [PubMed]

22. Koppolu, R.; Lahti, J.; Abitbol, T.; Swerin, A.; Kuusipalo, J.; Toivakka, M. Continuous Processing of Nanocellulose and Polylactic Acid into Multilayer Barrier Coatings. ACS Appl. Mater. Interfaces 2019, 11, 11920-11927. [CrossRef] [PubMed]

23. Hubbe, M.A.; Ferrer, A.; Tyagi, P.; Yin, Y.; Salas, C.; Pal, L.; Rojas, O.J. Nanocellulose in Thin Films, Coatings, and Plies for Packaging Applications: A Review. BioResources 2017, 12, 2143-2233. [CrossRef]

24. Österberg, M.; Vartiainen, J.; Lucenius, J.; Hippi, U.; Seppälä, J.; Serimaa, R.; Laine, J. A Fast Method to Produce Strong NFC Films as a Platform for Barrier and Functional Materials. ACS Appl. Mater. Interfaces 2013, 5, 4640-4647. [CrossRef]

25. Mesic, B.; Cairns, M.; Järnstrom, L.; Joo le Guen, M.; Parr, R. Film formation and barrier performance of latex based coating: Impact of drying temperature in a flexographic process. Prog. Org. Coat. 2019, 129, 43-51. [CrossRef]

26. Kiefer, S.; Robens, E. Some intriguing items in the history of volumetric and gravimetric adsorption measurements. J. Therm. Anal. Calorim. 2008, 94, 613-618. [CrossRef]

27. ASTM D3985-17 Standard Test Method for Oxygen Gas Transmission Rate Through Plastic Film and Sheeting Using a Coulometric Sensor; ASTM International: West Conshohocken, PA, USA, 2017.

28. TAPPI T 559, C.-12 TAPPI T 559 cm-12. Grease Resistance Test for Paper and Paperboard; TAPPI Press: Atlanta, GA, USA, 2012.

29. Wang, L.; Chen, C.; Wang, J.; Gardner, D.J.; Tajvidi, M. Cellulose nanofibrils versus cellulose nanocrystals: Comparison of performance in flexible multilayer films for packaging applications. Food Packag. Shelf Life 2020, 23, 100464. [CrossRef]

(C) 2020 by the authors. Licensee MDPI, Basel, Switzerland. This article is an open access article distributed under the terms and conditions of the Creative Commons Attribution (CC BY) license (http://creativecommons.org/licenses/by/4.0/). 